Bảng 3.11. Kêt quả khảo sát mức độ lo âu lan tóa theo thang Zung

\begin{tabular}{|c|c|c|}
\hline Mức độ lo âu & $\begin{array}{c}\text { Chỉ số thống kế } \\
\text { Số lượng } \\
\text { (n) }\end{array}$ & $\begin{array}{c}\text { Tỷ lệ } \\
\text { (\%) }\end{array}$ \\
\hline Bình thương (<40 điếm) & 21 & 65,63 \\
\hline $\begin{array}{c}\text { Lo âu lan tỏa nhe } \\
\text { (40-49 điểm) }\end{array}$ & 9 & 28,12 \\
\hline $\begin{array}{c}\text { Lo âu lan tỏa vừa } \\
\text { (50-59 điểm) }\end{array}$ & 2 & 6,25 \\
\hline $\begin{array}{c}\text { Lo âu lan tỏa nằng } \\
\text { (60-69 điểm) }\end{array}$ & 0 & 0 \\
\hline
\end{tabular}

Bảng 3.11 cho thấy có $34,37 \%$ bệnh nhân có rối loạn lo âu lan tỏa; trong đó có $3,12 \%$ bệnh nhân có cơn hoảng sơ kịch phát. Môt số nghiên cứu của Syed M.J. (2019) cũng có kểt quả tương tự, trong số bệnh nhân bị xuất huyết có trầm cảm thì $30 \%$ có rối loạn lo âu lan tỏa đi kèm và $60 \%$ bệnh nhân có rối loạn lo âu lan tỏa thì bị trầm cảm [8].

\section{KẾT LUÂ̂N}

Nghiên cứu đặc điểm rối loạn trầm cảm ở 32 bệnh nhân bị xuất huyết não, chúng tôi thấy:

- Trầm cảm diễn biến kéo dài (trung bình $4,95 \pm 2,16$ tháng) và hay tái phát. Các triệu chứng rối loạn trầm cảm đa dạng và hay gặp nhất là mất quan tâm hứng thú là $78,12 \%$ và giảm năng lượng với tỷ lệ là 65,62\%.

- Triệu chứng rối loạn vận động: vận động chậm chạp với $96,87 \%$ và có $28,12 \%$ bệnh nhân có ý tưởng tự sát. Triệu chứng rối loạn hình thức tư duy: có $78,12 \%$ bệnh nhân có ngôn ngữ chậm chạp và $59,38 \%$ bệnh nhân có nội dung ngôn ngữ nghèo nàn.

- Rối loạn trầm cảm theo đánh giá bằng thang Beck có $96,88 \%$ có test Beck từ 14 điểm trở lên tương đương với rối loạn trầm cảm ở các mức độ khác nhau, trong đó là trầm cảm mức độ vừa và nặng chiếm tỷ lệ $84,38 \%$ và có $34,37 \%$ bệnh nhân có rối loạn lo âu lan tỏa.

\section{TÀI LIẸU THAM KHẢO}

1. Lu Q., Chen L., Zeng J., et al. (2016), "Clinical Features of Liver Cancer with Cerebral Hemorrhage", Med Sci Monit; 22: 1716-1723.

2. Ngô Thị Kim Trinh, Lê Thị Cẩm Linh, Đào Thị Thanh Nhã và CS (2018), "Nghiên cứu đặc điểm xuất huyết não tại bệnh viện Nhân Dân $115^{\prime \prime}, Y$ học TP. Hồ Chí Minh, 22: 1.

3. Phạm Đình Đài (2011), "Nghiên cứu đặc điểm lâm sàng, cận lâm sàng, kêt quả sau điều trị nội mạch ở bệnh nhân đột quy chảy máu do vỡ phình động mạch não", Luận án tiến sĩ y học, Học viện Quân y.

4. Kofler M., Schiefecker A.J. and Gaasch $M$. (2019), "A reduced concentration of brain interstitial amino acids is associated with depression in subarachnoid hemorrhage patients", Sci Rep; 9(1): 2811.

5. King J.T., Kassam A.B., Yonas $H_{.}$, et al. (2005), "Mental health, anxiety, and depression in patients with cerebral aneurysms", ] Neurosurg; 103(4): 636-641.

6. Baranich A.I., Savin I.A., Tabasaranskiy T.F., at al. (2018), "Disturbances of the hemostatic system in patients with aneurysmal subarachnoid hemorrhage", Zh Vopr Neirokhir Im N N Burdenko; 82(4): 109-116.

7. Lee B.H., Kim E.J., Ku B.D. et al. (2008), "Cognitive impairments in patients with hemispatial neglect from acute right hemisphere stroke", Cogn Behav Neurol; 21(2): 73-76.

8. Syed M.J., Farooq S., Siddiqui S., et al. (2019), "Depression and the Use of Selective Serotonin Reuptake Inhibitors in Patients with Acute Intracerebral Hemorrhage", Cureus; 11(10): e5975.

\title{
NGHIÊN CỨU ĐĂC ĐIỂM LÂM SÀNG, CÂAN LÂM SÀNG VÀ DI TRUYỀn CỦA NHỮNG BỆNH NHÂN VÔ SINH KHÔNG Có TINH TRÙNG KHÔNG DO TẮC
}

\section{TÓM TẮT}

Để nhận biết các đặc điểm lâm sàng, cận lâm sàng và các bất thường di truyền liên quan đến tình trang không có tinh trùng không do tắc, chúng tôi tiến hành nghiên cứu trên 501 bênh nhân nam vô sinh không có tinh trùng không do tẳc. Kết quả cho thấytuổi trung

\section{${ }^{1}$ Trường Đại học Y Hà Nọi,}

²Bệnh viện Đại học Y Hà Nội.

Chịu trách nhiệm chính: Nguyễn Hoài Bắc

Email: nguyenhoaibac@hmu.edu.vn

Ngày nhận bài: 19.10.2020

Ngày phản biên khoa họ: 23.11.2020

Ngày duyệt bài: 4.12.2020

\section{Nguyễn Hoài Bắc ${ }^{1,2}$, Trần Văn Kiên ${ }^{2}$, Hoàng Long ${ }^{1}$}

bình của nhóm nghiên cứu là $29,8 \pm 5,5$ tuổi. Tỷ lệ vô sinh nguyên phát chiếm $90,3 \%$. Tiền sử viêm tinh hoàn do quai bị chiếm tỉ lệ 38,6\%. Nồng độ hormon $\mathrm{FSH}$, LH, Testosterone huyết thanh trung bình lần lượt là $31,6 \pm 16,5 \mathrm{mIU} / \mathrm{ml}, 15,5 \pm 10 \mathrm{mIU} / \mathrm{ml}, 12,8 \pm$ $7,13 \mathrm{nmol} / \mathrm{l}$. Bất thường NST chiếm tỉ lệ 30,7\%, trong đó bất thường số lượng NST với Karyotype 47,XXY chiếm tỉ lệ $27,3 \%$. Đột biến mất đoạn nhỏ AZF chiếm tỉ lệ $13,8 \%$, trong đó mất đoạnAZFc có tỉ lệ cao nhất với 42,1\%, mất đoạn AZFa 2,6\%, mất đoạn AZFd chiếm $5,3 \%$, không có mất đoan $A Z F b$ đơn độc mà phối hợp với các mất đoạn khác với tỉ lệ là $34,2 \%$. Nghiên cứu của chúng tôi cho thấy viêm tỉnh hoàn do quai bị và các bất thường di truyền là những nguyên nhân chính dẫn tới tình trạng không có tinh trùng không do tắc ở những nam giới vô sinh. Do vậy cần 
phải khai thác tiên sử viêm tinh hoàn do quai bị và xét nghiệm sàng lọc các bất thường di truyền ở những nam giới vô sinh không có tinh trùng không do tắc

Tư Khóa: Vô sinh không có tinh trùng, vô sinh không có tinh trùng không do tắc, NST, AZF.

\section{SUMMARY}

\section{STUDY ON CLINICALAND GENETIC} CHARACTERISTICS OF MALE PATIENTS WITH NON-OBSTRUCTIVE AZOOSPERMIA

We examined 501 patients with non-obstructive azoospermia to evaluate clinical, subclinical, and genetic characteristics. The results show that the average age of patients in the study was $29.8 \pm 5.5$ years. Primary infertility accounts for the majority, with a rate of $90.3 \%$. There was $38.6 \%$ of patients had a history of mumps orchitis. The average level of $\mathrm{FSH}$, LH, Testosterone were $31.6 \pm 16.5 \mathrm{mIU} / \mathrm{ml}, 15.5$ $\pm 10 \mathrm{mIU} / \mathrm{ml}, 12.8 \pm 7.13 \mathrm{nmol} / \mathrm{l}$, respectively. The prevalence of chromosomal abnormalities was $30.7 \%$. Of these, the chromosomal quantity abnormalities with Karyotype 47, XXY (Klinefelter syndrome) accounted for $27.3 \%$. The incidence of AZF microdeletion was $13.8 \%$. Of these, AZFc deletion was the most common at the rate of 42.1, AZFa deletion, which accounted for $2.6 \%$, were the least prevalent, and the frequency of AZFd deletion was $5.3 \%$. However, there was no single AZFb deletion, which combined with other AZF deletions with $34,2 \%$.Our research shows that mumps orchitis and chromosomal abnormalities are the leading causes of azoospermia. Screening for genetic abnormalities plays an important role in infertile patients with non-obstructive azoospermia.

Key word: Azoospermia, Non-obstructive azoospermia, Chromosome, AZF

\section{I. ĐẶT VẤN ĐỀ}

Hiện nay,vô sinh đang dân trở thành gánh nặng cho xã hội, là mối quan tâm, lo lắng của các căp vợ chồng hiếm muôn. Theo thống kê của các nghiên cứu trên thế giới, tỷ lệ vô sinhchiếm khoảng $15 \%$ các cặp vợ chồng. Trong các trường hợp vô sinh nam, vô sinh do không có tinh trùngcó ảnh hưởng nặng nề nhất tới chức năng sinh sản, làm cho nam giới không thể có con theo cách tự nhiên mà phải dùng các biện pháp hỗ trợ sinh sản.

Trong các trường hợp vô sinh không có tinh trùng, những bệnh nhân không có tinh trùng không do tắc (NOA) có sự tổn thương rất nặng nề của quá trình sinh tinh và nhiều trường hợp phải sử dụng tinh trùng hiến tặng. Trích xuất tinh trùng từ tinh hoàn (TESE, micro-TESE) kết hợp với IVF/ICSI là lựa chọn duy nhất để điêuu trị vồ sinh cho những bênh nhân vô sinh không có tinh trùng không do tắc. Tuy nhiên, TESE không thể tìm thây tinh trùng ở tất cả bệnh nhân. Nhiều yếu tố dư đoán đước cho là có ảnh hưởng đến sự thành cồng của viêc lấy tinh trùng từ tinh hoàn đã được nghiên cứu như tuổi tác, chỉ số khối cơ thể (BMI), tiền sử bệnh tật, kích thước tinh hoàn, các bất thường cơ quan sinh dục, các thông số nội tiết tố và các bất thường di truyền [6]. Trong thực tế lâm sàng để giảm bớt gánh nặng kinh tế cho điều trị và để tránh các can thiệp không cần thiết việc tìm hiểu các đặc điểm lâm sàng và cận lâm sàng của những bệnh nhân vô sinh không có tinh trùng không do tắc là rất cần thiêt, giúp các bác sĩ lâm sàng đưa ra những tư vấn, hướng điều trị phù hợp và tiên lượng điều trị cho từng trường hợp.

Tại Việt Nam,cho tới nay mới chỉ cómột vài nghiên cứu nhỏ về vấn đề vô sinh nam không có tinh trùng[1][2]. Những nghiên cứu này tập trung chủ yếu nghiên cứu kết quả điều trị cho những bệnh nhân vô sinh không có tinh trùng. Số lượng những nghiên cứu về đặc điểm lâm sàng và cận lâm sàng của những bệnh nhân NOA còn nhiều han chế. Chính vì vây, chúng tôi tiến hành đề tài: "Nghiên cứu đặc điểm lâm sàng, cận lâm sàng và đặc điểm di truyền của những bệnh nhân vô sinh không có tinh trùng không do tắc" nhằm mục tiêu sau:

1. Mô tả các đặc điểm lâm sàng và cận lâm sàng của những bệnh nhân vô sinh không có tinh trùng không do tắc.

2. Xác định các bất thường di truyền liên quan đến tình trạng không có tinh trùng không do tắc.

\section{II. ĐỐI TƯợNG VÀ PHƯƠNG PHÁP NGHIÊN CỨU}

1. Đối tượng nghiên cứu: Nghiên cứu được thực hiện trên các bệnh nhân nam vô sinh không có tinh trùng khám tại Bệnh viện Đại học Y Hà Nội từ tháng 4 năm 2013 đến tháng 10 năm 2019.

Tiêu chuẩn lựa chọn: - Bệnh nhân trong độ tuổi sinh sản từ 18-55 tuổi.

- Bệnh nhân đã thực hiện 2 mẫu tinh dịch đồ những không có tinh trùng trong tinh dịch.

-Bệnh nhân được chọn dựa vào tiêu chuẩn chẩn đoán vô sinh không có tỉnh trùng không do tắc của Huang I.S.[7] với $F S H>9,2 \mathrm{mIU} / \mathrm{ml}$ và trên siêu âm kích thước tinh hoàn 2 bên trung bình $<15 \mathrm{ml}$.

- Bệnh nhân được đánh giá đầy đủ về các đặc điểm lẩm sàng, cận lâm sàng và di truyền.

\section{Phương pháp nghiên cứu:}

- Thiêt kế nghiên cứu: Mô tả cắt ngang, chọn mẫu thuân tiên

- Xử lý số liệu: Xử lý số liệu bằng phần mềm R. Sử dụng thống kê mô tả số lượng, tỷ lệ phần trăm, mean, độ lệch chuẩn, Min, Max, mức $\mathrm{p}<0,05$ được coi là có ý nghĩa thống kê. 
III. KẾT QUẢ NGHIÊN CỨU

1. Đặc điểm lâm sàng của nhóm nghiên cứu.

Bảng 1: Đặc điểm chung của nhóm nghiên cứu

\begin{tabular}{|c|c|c|c|c|c|}
\hline Đặc điếm & $\mathbf{N}$ & $\mathbf{\%}$ & Mean \pm SD & Median & Min-Max \\
\hline Tuối (năm) & 501 & & $29,8 \pm 5,5$ & 29,0 & $15,0-51,0$ \\
\hline Chiêu cao $(\mathrm{cm})$ & 501 & & $167,7 \pm 6,02$ & 168,0 & $139,0-187,0$ \\
\hline Cân nặng $(\mathrm{kg})$ & 501 & & $62,4 \pm 9,22$ & 62,0 & $41,0-100$ \\
\hline BMI (kg/m $)$ & 501 & & $22,2 \pm 2,92$ & 22,0 & $15,7-33,3$ \\
\hline$<18.5$ & 54 & $11,2 \%$ & & & \\
\hline $18.5-23$ & 257 & $53,3 \%$ & & & \\
\hline$>23$ & 171 & $35,5 \%$ & & & \\
\hline Hút thuốc lá & 444 & & & & \\
\hline Có & 99 & $22,3 \%$ & & & \\
\hline Không & 345 & $77,7 \%$ & & & \\
\hline Tiền sử viêm tinh hoàn do quai bị & 306 & & & & \\
\hline Có & 118 & $38,6 \%$ & & & \\
\hline Không & 188 & $61,4 \%$ & & & \\
\hline Phân loại vồ sinh & 371 & & & & \\
\hline Nguyền phát & 335 & $90,3 \%$ & & & \\
\hline Thứ phát & 36 & $9,7 \%$ & & & \\
\hline
\end{tabular}

Tỷ lệ bệnh nhân có tiền sử viêm tinh hoàn do quai bị chiếm tới 38,6\%.

2. Đặc điểm cận lâm sàng của nhóm nghiên cứu

Bảng 2: Đặc đ̛iếm cận lâm sàng của nhóm nghiên cứu

\begin{tabular}{|c|c|c|c|c|c|}
\hline Đăc điếm & $\mathbf{n}$ & $\mathbf{\%}$ & Mean \pm SD & Median & Min - Max \\
\hline $\mathrm{LH}(\mathrm{mIU} / \mathrm{ml})$ & 501 & & $15,5 \pm 10$ & 12,2 & $1,80-63,2$ \\
\hline$<=7.6$ & 105 & $21,0 \%$ & & & \\
\hline$>7.6$ & 396 & $79,0 \%$ & & & \\
\hline Testosterone $(\mathrm{nmol} / \mathrm{l})$ & 501 & & $12,8 \pm 7,13$ & 11,6 & $0,43-48,3$ \\
\hline$<12$ & 265 & $52,9 \%$ & & & \\
\hline$>=12$ & 236 & $47,1 \%$ & & & \\
\hline Thế tích tinh hoàn phải (ml) & 501 & & $5,56 \pm 3,51$ & 5,44 & $0,37-14,9$ \\
\hline$<12$ & 479 & $95,6 \%$ & & & \\
\hline$\geq 12$ & 22 & $4,4 \%$ & & & \\
\hline Thế tích tinh hoàn trái (ml) & 501 & & $5,52 \pm 3,34$ & 5,44 & $0,05-14,8$ \\
\hline$<12$ & 482 & $96,2 \%$ & & & \\
\hline$\geq 12$ & 19 & $3,8 \%$ & & & \\
\hline Tinh dịch đồ: $\mathrm{pH}$ & 487 & & $7,49 \pm 0,44$ & 7,50 & $5,00-9,00$ \\
\hline$<7.2$ & 46 & $9,4 \%$ & & & \\
\hline$>=7.2$ & 441 & $90,6 \%$ & & & \\
\hline Thế tích (ml) & 493 & & $2,47 \pm 1,4$ & 2,50 & $0,20-9,80$ \\
\hline$<1.5$ & 119 & $24,1 \%$ & 31,6 & 29,2 & $9,23-131,2$ \\
\hline$>=1.5$ & 374 & $75,9 \%$ & 5,56 & 5,44 & $0,37-20,1$ \\
\hline
\end{tabular}

Nồng độ $\mathrm{FSH}$, LH trong huyết thanh của nhóm nghiển cứu tăng cao so với giá trị bình thường, trong khi nồng độ Testosterone trung bình trong huyết thanh trong giới hạn bình thường. Thể tích tinh hoàn trung bình 2 bên của nhóm nghiên cứu nhỏ hơn so với giới hạn bình thường.pH và thể tích tinh dịch trung bình của nhóm đối tượng nghiên cứu hầu hết đều nằm trong giới hạn bình thường.

3. Đặc điểm di truyên của nhóm bệnh nhân nghiên cứu

Bảng 3: Đặc điểm nhiễm sắc thể đồ của

nhóm nghiên cứu
\begin{tabular}{|c|c|c|}
\hline Đặc điếm & $\mathbf{N}$ & $\mathbf{\%}$ \\
\hline Đột biến số lượng & $80 / 286$ & $28,0 \%$ \\
\hline Monosomy $(X O / X Y)$ & $1 / 286$ & $0,3 \%$ \\
\hline Trisomy $(X X Y)$ & $78 / 286$ & $27,3 \%$ \\
\hline Tetrasomy $(X X X Y)$ & $1 / 286$ & $0,3 \%$ \\
\hline Đột biến cấu trúc & $6 / 286$ & $2,1 \%$ \\
\hline Đa hình NST & $1 / 286$ & $0,3 \%$ \\
\hline Karyotype 46, XX & $1 / 286$ & $0,3 \%$ \\
\hline Karyotype $46, X Y$ & $198 / 286$ & $69,3 \%$ \\
\hline Tống & $\mathbf{2 8 6}$ & $\mathbf{1 0 0 \%}$ \\
\hline
\end{tabular}

Kết quả khả sát nhiễm sắc thể đồ của 286 
bệnh nhân cho thãy tỉ lệ bất thường nhiễm sắc thể đồ chiếm 30,7\%, phần lớn là đột biến số lượng NST chiếm tỉ lệ $28 \%$, trong đó hội chứng Klinefelter chiếm tỉ lệ cao nhất $27,3 \%$.

Bảng 4: Đặc điểm đột biến vi mât đoạn AZF trên NST giới tính $Y$

\begin{tabular}{|c|c|c|c|}
\hline Đặc điểm & $\mathbf{N}$ & $\begin{array}{c}\mathbf{\%} \\
(\mathbf{N = 2 7 6 )}\end{array}$ & $\begin{array}{c}\mathbf{\%} \\
(\mathbf{n = 3 8 )}\end{array}$ \\
\hline AZF a & $1 / 276$ & $0,4 \%$ & $2,6 \%$ \\
\hline AZF c & $16 / 276$ & $5,8 \%$ & $42,1 \%$ \\
\hline AZF d & $2 / 276$ & $0,7 \%$ & $5,3 \%$ \\
\hline AZF c + d & $6 / 276$ & $2,2 \%$ & $15,8 \%$ \\
\hline AZF b + c & $2 / 276$ & $0,7 \%$ & $5,3 \%$ \\
\hline AZF b+c+d & $6 / 276$ & $2,2 \%$ & $15,8 \%$ \\
\hline AZF a +b+c & $3 / 276$ & $1,1 \%$ & $7,8 \%$ \\
\hline AZF a+b+c+d & $2 / 276$ & $0,7 \%$ & $5,3 \%$ \\
\hline Tống & $\mathbf{3 8 / 2 7 6}$ & $\mathbf{1 3 , 8 \%}$ & $\mathbf{1 0 0} \%$ \\
\hline
\end{tabular}

Trong số 276 bệnh nhân được làm đột biến AZF cho thây mất đoạn AZF chiếm tỉ lệ 13.8\%.

\section{BÀN LUÂN}

Trong thực hành lâm sàng việc chẩn đoán chính xác nguyên nhân không có tinh trùng trong tinh dịch là rất quan trọng, nó giúp các bác sĩ tiên lượng và đưa ra những phương pháp điều trị phù hợp cho những bệnh nhân vô sinh nam. Tuy nhiên việc chẩn đoán phân biệt giữa các nguyên nhân không có tinh trùng là không hề đơn giản. Để chẩn đoán xác định nguyên nhân không có tinh trùng thì sinh thiết tinh hoàn đóng vai trò quyết định, tuy nhiên phương pháp này mang tính xâm lấn và nhiều nguy cơ biến chứng. Để tránh các can thiệp xâm lấn, chúng tôi lấy giá trị tham khảo trong nghiên cứu của Huang I.S[7] làm tiêu chẩn để lựa chọn những bệnh nhân NOA dựa trên nồng độ FSH và kích thước tinh hoàn để đưa vào nghiển cứu. Trong nghiên cứu của Huang I.S sử dụng kết hợp giá trị FSH > 9,2 $\mathrm{mIU} / \mathrm{ml}$ và kích thước tinh hoàn $<15 \mathrm{ml}$ có giá trị dự đoán NOA là 99,2\%.

Khai thác tiền sử bệnh chúng tôi nhận thấy có tới 38,6\% đối tượng nghiên cứu có tiền sử viêm tinh hoàn do quai bị.Vi-rút quai bị có ái tính cao với nhu mô tinh hoàn, dẫn tới hiện tượng phù nề nhu mô kèm theo sung huyết ổng sinh tinh và hậu quả là hoại tử kèm theo quá trình hyalin hóa ông sinh tinh và xơ teo tinh hoàn. Các báo cáo trước đây cho thấy tỉ lệ biến chứng sưng đau tinh hoàn xảy ra ở $15-40 \%$ nam giới sau tuổi dậy thì bị nhiễm virus quai bị[4]. Có tới 30-50\% bệnh nhân có biến chứng teo tinh hoàn và $13 \%$ bệnh nhân có biến chứng vô sinh sau viêm tinh hoàn do quai bị.Vì vậy cần phải nâng cao ý thức cộng đồng về các biện pháp phòng chống quai bị, cũng như có các biện pháp điều trị tích cực cho những bệnh nhân có viêm tinh hoàn do quai bị để phòng tránh các biến chứng có thể ảnh hưởng tới chức năng sinh sản.

Trong cơ chế điều hòa sinh tinh trùng và testosterone có mối quan hệ chặt chẽ của trục hạ đồi- tuyến yên - tinh hoàn. Chính vì vậy FSH, LH và testosterone được xem như những chỉ số đánh giá chức năng hoạt động của tinh hoàn. Trong nghiên cứu của chúng tôi,nồng độ testosterone trung bình ở phần lớn đối tượng nghiên cứu nằm trong giới hạn bình thường, trong khi nông độ FSH và LH ở phần lớn đối tượng nghiên cứu ở mức tăng rất cao. Nghiên cứu của Goluza[5] cũng cho thấy nồng độ Testosterone ở hầu hết các bênh nhân không có tinh trùng không do tắc đều nằm trong giới hạn bình thường và nồng độ $\mathrm{FSH}$, LH tăng cao trong huyết thanh. Tác giả cho rằng ở hầu hết những bệnh nhân không có tinh trùng không do tắc có sự tổn thương các tế bào mầm tinh và suy giảm chức năng sinh tinh trùng của hoàn, còn các tế bào Leydig chỉ bị tổn thương một phần và có sự hoạt động bù chức năng của các tế bào Leydig bình thường còn lại dưới sự kích thích của nồng độ LH cao trong máu, đảm bảo sản xuất đủ testosterone để duy trì mức huyết thanh bình thường.

Vô sinh nam giới do nhiều nguyên nhân gây nên, các nghiên cứu đã chỉ ra rằng những bất thường về di truyền tế bào và phân tử như bất thường về số lượng nhiễm sắc thể (NST) hoặc đột biến trên NST giới tính Y là các nguyên nhẩn di truyền chính gây vô sinh ở nam giới, đặc biệt ở những bệnh nhân NOA. Nghiên cứu đặc điểm di truyền của nhóm đối tượng nghiên cứu chúng tôi cho thấy tỉ lệ bất thường NST đồ chiếm tỉ lệ khá cao lên tới 30,7\%, trong đó đột biến số lượng NST với Karyotype 47, XXY chiếm phần lớn với tỉ lệ 27,3\%. Theo các thống kê trước đây, tỉ lệ bất thường di truyền ở những bệnh nhân vô sinh không có tinh trùng dao động từ 20-30\%, đột biến số lượng NST với Karyotype 47,XXY chiếm 10-20\%[8]. So với các nghiên cứu trên, tỉ lệ bất thường di truyền và tỉ lệ bệnh nhân vô sinh mắc hội chứng Klinefelter trong nghiên cứu của chúng tôi có tỉ lệ cao hơn do tiêu chuẩn lựa chọn của chúng tôi tập trung vào những bệnh nhân NOA. Nhìn chung ở tất cả các nghiên cứu, tỉ lệ bất thường NST, trong đó đột biến số lượng NST với Karyotype 47, XXY chiếm tỉ lệ khá cao.

Ngoài nguyên nhân do rối loạn NST thì rối loạn di truyền ở mức độ phân tửmất đoạn nhỏ trển NST Y là nguyên nhân di truyền thứ hai gây vô sinh không có tinh trùng ở nam giới. Các 
nghiên cứu trước đây cho thấy tỉ lệ mất đoạn nhỏ AZF trên NST Y ở nam giới vô sinh dao động từ $5-15 \%[3],[8]$, tỉ lệ này trong nghiên cứu của chúng tôi là $13,8 \%$. Mất đoạn giữa các vùng AZF khác nhau thường xuất hiện với tỉ lệ khác nhau, trong nghiên cứu của Lee J.Y cho thấy mất đoạn AZFc chiếm tỉ lệ cao nhất $60 \%$, tiếp đến là AZFb $16 \%$, AZFa chiếm $5 \%$ và mất đoạn phối hợp 14\%[8]. Trong nghiên cứu của Lương Thi Lan Anh trên 30 bệnh nhân vô sinh không có tinh trùng[1], tỉ lệ mất đoạn AZFc chiếm 46,7\%, mất đoạn AZFb chiếm 16,6\%, không phát hiện mất đoạn AZFa, mất đoạn AZFd chiếm tỉ lệ $6,7 \%$. So sánh với nghiên cứu của chúng tôi nhận thây tỉ lệ mất đoạn AZFc cũng có tỉ lệ cao nhất với $42,1 \%$ và chiểm tỉ lệ thấp nhất là $A Z F a$ với 2,6\%. Đột biến mất đoạn AZFd chiếm 5,3\%.Chúng tổi không nhận thây mất đoạn AZFb đơn độc mà chỉ phối hợp với các đột biến mất đoạn khác với tỉ lệ là $34,2 \%$. Sự khác nhau giữa các nghiên cứu có thể có liên đến chủng tộc, từng nhóm dân cư và đối tượng nghiên cứu khác nhau. Như vậycùng với xét nghiệm NST đồ, xét nghiệm tìm đột biến mất đoạn nhỏ trên NST Y có ý nghĩa lâm sàng quan trọng trong việc chẩn đoán nguyên nhân cũng như tiên lượng khả năng tìm thây tinh trùng ở những bệnh nhân NOA, giúp cho bệnh nhân giảm thời gian và chi phí điêu trị cũng như tránh được những can thiệp không cần thiết.

\section{KẾT LUÂ̂N}

ở những bệnh nhân vô sinh nam không có tinh trùng không do tắc, tiền sử viêm tinh hoàn do quai bị chiếm tỉ lệ khá cao lên tới 38,6\%, cùng với các bất thường về di truyền được xem là những nguyên nhân chính dẫn tới tình trạng không có tinh trùng không do tắc.

Tî lệ bất thường NST, đặc biệt bất thường số lượng NST với Karyotype 47, XXY và tỉ lệ mất đoạn AZF chiếm tỉ lệ khá cao, cho thấy vai trò quan trọng của xét nghiệm sàng lọc tìm nguyên nhân do các bất thường di truyền ở những bệnh nhân vô sinh không có tinh trùng không do tắc.

\section{TÀI LIỆ THAM KHẢO}

1. Lương Thị Lan Anh và Hoàng Thu Lan, Ứng dụng kỹ thuật Real-time PCR phát hiện mất đoạn AZF ở bệnh nhân vô sinh nam không có tinh trùng. Khoa học và công nghệ Việt Nam, 2019, 61(2), tr. 8-12

2. Nguyễn Thành Như, Phạm Hữu Đương, và Nguyển Ngọc Tiến, Nhân 300 trường hợp trích tinh trùng tữ mào tinh hoàn và tinh hoàn để thực hiên vi thao tác tiêm tinh trùng vào bào tương trú́ng. Tap chí Y học Việt Nam, 2013, 403, tr. 302-312.

3. Nguyến Đức Như', Nghiên cứu đăc điểm nhiếm sắc thể và phát hiền mất đoạn AZFc ở bệnh nhân vô sinh nam giới. L̇uận văn Thạc sĩ Y học chuyên nghành Y sinh học - Di truyền, 2009.

4. Niall F Davis, Barry B McGuire, Jackie A Mahon và cộng sự, The increasing incidence of mumps orchitis: a comprehensive review. BJU international, 2010, 105(8), tr. 1060-1065.

5. Trpimir Goluža, Alexander Boscanin, Jessica Cvetko, và cộng sự, Macrophages and Leydig cells in testicular biopsies of azoospermic men. BioMed Research International, 2014.

6. Ahmad 0 Hammoud, A Wayne Meikle, Leonardo Oliveira Reis và cộng sự. Obesity and male infertility: a practical approach. in Seminars in reproductive medicine. 2012. Thieme Medical Publishers.

7. I. S. Huang, W. J. Huang, và A. T. Lin, Distinguishing non-obstructive azoospermia from obstructive azoospermia in Taiwanese patients by hormone profile and testis size. J Chin Med Assoc, 2018, 81(6), tr. 531-535.

8. Joo Yeon Lee, Rima Dada, Edmund Sabanegh, và cộng sứ, Role of genetics in azoospermia. Urology, 2011, 77(3),tr 598-601.

\section{MỐI LIÊN QUAN GIỮA HÀNH VI TÌNH DỤC VÀ CÁC BÊ̂NH LÂY NHIỄM QUA ĐƯỜNG TÌNH DỤC Ở NAM GIỚI}

TÓM TẮT.

\author{
${ }^{1}$ Bệnh viện Quân Y 175 \\ 2Trường Đại học Y Hà Nọi \\ ${ }^{3}$ Bênh viên Đai hơ Y Hà Nôi \\ Chịu trách nhiệm chính: Nguyễn Hoài Bắc \\ Email: nguyenhoaibac@hmu.edu.vn \\ Ngày nhận bài: 26.10.2020 \\ Ngày phản biện khoa họ: 27.11 .2020 \\ Ngày duyệt bài: 10.12 .2020
}

Vũ Thái Hoàng ${ }^{1}$, Nguyễn Hoài Bắc ${ }^{2}$, Nguyễn Cao Thắng ${ }^{3}$

Các bệnh lây nhiễm qua đường tình dục (STDs) là một trong các bệnh lý phổ biến ảnh hưởng đến sức khỏe cộng đồng tại nhiêu quốc gia, đặc biệt là các quốc gia đang phát triển như Việt Nam. Hoạt động tình dục không lành mạnh luôn được coi là những là nguyên nhân chính làm tăng tỉ lệ mắc các bệnh này. Chính vì vậy, chúng tôi tiển hành nghiên cứu trên 3005 bệnh nhân được lấy ngẫu nhiên trong số bệnh nhân đến khám tại Khoa Nam học và Y Học giới tính, Bệnh viện Đại Học Y Hà Nội để phân tích các ảnh hưởng của hành vi tình dục đếnkhả năng mắc STDs ở nam giới. Kết quả cho thấy độ tuổi quan hệ tình dục 